\title{
Patterning and Plasticity of the Cerebral Cortex
}

\author{
Mriganka Sur $^{1 *}$ and John L. R. Rubenstein ${ }^{2 *}$
}

The cerebral cortex of the human brain is a sheet of about 10 billion neurons divided into discrete subdivisions or areas that process particular aspects of sensation, movement, and cognition. Recent evidence has begun to transform our understanding of how cortical areas form, make specific connections with other brain regions, develop unique processing networks, and adapt to changes in inputs.

$\mathbf{T}$ he degree to which our genetic endowment (nature) versus our experiences (nurture) mold the development and function of our brains has been the subject of robust discussion and experimental investigation. Research before 1990 led to two general hypotheses: the Protomap (1) and the Protocortex (2). In their most extreme interpretations, the former postulated that the cortical progenitor zone contains the information that generates cortical areas, whereas the latter postulated that thalamic afferent axons, through activity-dependent mechanisms, impose cortical areal identity on an otherwise homogeneous cortex. In the intervening 15 years, tremendous strides have been made in understanding cortical development with molecular, genetic, imaging, and electrophysiological ap-

${ }^{1}$ Department of Brain and Cognitive Sciences, Massachusetts Institute of Technology, 77 Massachusetts Ave., 46-6237, Cambridge, MA 02139, USA. ${ }^{2} \mathrm{Nina}$ Ireland Laboratory of Developmental Neurobiology, 1550 4th Street, 2nd Floor South, Room GD 284C, University of California at San Francisco, San Francisco, CA 94143-2611, USA.

*To whom correspondence should be addressed: E-mail: msur@mit.edu (M.S.); john.rubenstein@ucsf. edu (J.L.R.R.)

A

Signaling centers generate positional information
B

Graded expression of transcription factors transduces positional information

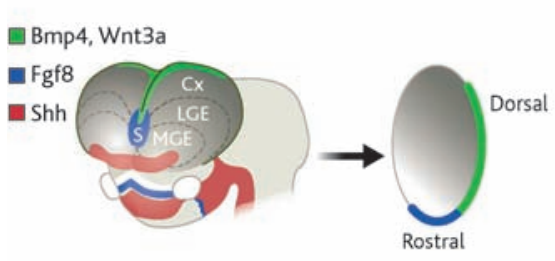

proaches. The new evidence indicates that the development of cortical areas involves a rich array of signals, with considerable interplay between mechanisms intrinsic to cortical progenitors and neurons and mechanisms extrinsic to the cortex, including those requiring neural activity.

\section{Early Patterning of the Cortex}

Early development of the cortex is highly integrated with development of other parts of the brain, including midline patterning centers, the basal ganglia primordia that produce many of the cortical local circuit neurons, and axonal inputs from the thalamus and brain stem. The cortex, more generally known as the pallium, develops from a morphologically uniform ventricular zone located in the dorsocaudal part of the telencephalic vesicles. The pallium is further subdivided into medial pallium (MP), dorsal pallium (DP), lateral pallium (LP), and ventral pallium (VP), which will respectively give rise to the hippocampal formation (limbic lobe), the neocortex, the olfactory/piriform cortex, and the claustrum and parts of the amygdala $(3,4)$. Each of these large domains is divided into subdomains, such as the functional subdivisions (areas) of the neocortex.
Mature cortical areas differ by their location within the cortex, molecular properties, histological organization, patterns of connectivity, and function. Within the neocortex, rostral regions regulate motor and executive functions, whereas caudal regions process somatosensory, auditory, and visual inputs. These different cortical areas have a precise connectivity, particularly with nuclei within the dorsal thalamus, which provides some of the principal inputs to the cerebral cortex (Fig. 1).

Programs of regional identity and morphogenesis in the pallium are directed in part by signaling centers producing secreted molecules. These centers are initially located along the edges and midline of the neural plate and later along and flanking the midline of the telencephalic vesicles (Fig. 2A) (3, 5-8). Sonic hedgehog ( $\mathrm{Shh}$ ) is expressed in the ventral telencephalon and hypothalamus. Shh is essential to the regionalization of the subpallium and also regulates morphogenesis and patterning of the pallium $(9-11)$. Along the dorsal midline, secreted molecules of the bone morphogenetic protein (Bmp) and Wnt families control patterning of the medial and dorsal pallium, including the hippocampus and neocortex and the choroid plexus $(12,13)$. The targeted inactivation of Wnt3a, or of the Wnt signaling factor Lef-1, severely disrupts the formation of the hippocampus $(14,15)$. Ectopic expression and reduction of Bmp signaling alters development of the dorsal midline and paramedial structures (i.e., choroid plexus) 
(16) and also affects patterning of the dorsal pallium $(9,13,17,18)$.

At the rostral margin of the telencephalon, a source of Fgf8 promotes telencephalic outgrowth and regulates its rostral regionalization $(5,8,19-23)$. Fgf8 expression in the rostral telencephalon is nested within the expression of other Fgfs (24). Mutations in the mouse and zebrafish Fgf8 gene and experimental manipulations of Fgf8 function have demonstrated its dosage-dependent functions, including regulation of the size and nature of the frontal cortex, telencephalic midline structures, and basal ganglia (19-21, 23, 25-28). The phenotypic complexity reflects, in part, reciprocal interactions between the patterning centers. For instance, Bmp4 expression and apoptosis decrease in the rostral midline of Fgf8 hypomorphs, whereas they increase when Fgf8 expression approaches the null state (23). Thus, the level of Fgf8 regulates the level of Bmp4 expression in a nonmonotonic manner, which in turn leads to different effects on the patterning and survival of dorsal midline cells as a function of Fgf8 dosage, perhaps through expression of Sprouty (29), an Fgf8induced repressor of receptor tyrosine kinase signaling (Fig. 2B).

An intriguing concept that arises from these studies is that alterations in the relative strengths of the patterning centers would lead to modifications in the relative sizes of different cortical regions. For instance, an animal with a weak Fgf-patterning center would be expected to have a relatively small prefrontal cortex and therefore might exhibit a cognitive profile found in "hypofrontal" patients. Ectopic Fgf8 expression can duplicate somatosensory cortex, which shows that it can specify regional fate and suggests a mechanism for how new cortical areas could evolve $(19,30)$.

The patterning centers operate in part through generating graded expression of the transcription factors that control histogenetic programs for proliferation, neurogenesis, migration, connectivity, and cell death/survival. Several genes encoding transcription factors, including Foxg1 (BF1), COUPTF1, Emx2, Lef1, Lhx2, and Pax6, are expressed in gradients along the mediolateral (dorsoventral) and rostrocaudal axes of the cerebral cortex $(15,31-37)$. Alteration in Fgf8 signaling regulates the expression of several transcription factors (Fig. 2B); for instance, Fgf8 increases Foxg1 (BF1) expression and reduces Emx 2 and COUPTF1 expression $(5,20,22,28,38)$. Analysis of mice lacking COUPTF1, Emx2, Foxg1, Gli3, Lhx2, Pax6, and Tlx demonstrates that these transcription factors are essential for regionalization of the cortex. Progenitors in Foxg1 and Lhx2 mutants exhibit expansion of dorsalmost molecular features (Bmp and Wnt expression) $(37,39,40)$; Emx2 and Pax6 also regulate expression from the patterning centers $(8,28,36)$. Foxg1 inhibits differentiation and promotes proliferation $(37,40)$. Gli3 represses ventral fates $(10,11,41,42)$. Pax6 and Tlx regulate the formation of the ventral pallium and its boundaries (43-45). Pax6 is also involved in specifying rostral identify (32), and COUPTF1 in regulating caudoventral identity $(46,47)$.

In Emx2 $2^{-1-}$ neonatal mice, the occipital cortex (presumptive visual cortex) adopts molecular fate characteristics of the parietal neocortex (presumptive somatosensory cortex) $(33,37,47,48)$. This molecular shift correlates with a corresponding shift in thalamic projections, raising the possibility that molecular properties and the targeting of thalamic axons are controlled by Emx2 expression. Subtle increases or decreases in Emx2 expression lead to expansions or contractions in the relative sizes of neocortical subdivisions (37, 46, 47, 49-51).

The programs of regionalization are linked to the programs of neurogenesis, which influence laminar identity and therefore the input and output projections of a cortical area. The prevailing model is that cortical glutamatergic projection neurons of the subplate and layers 6 to 2 are produced sequentially by the cortical progenitors (1), cortical GABAergic $(\gamma$-aminobutyric acid) local circuit neurons are produced by the subpallial progenitors (52), and Cajal Retzius cells of layer 1 are produced in the dorsal-most pallium (37). The subplate and layer 6 send projections to the thalamus; layer 5 sends projections to the basal ganglia as well as to the thalamus, midbrain, and brain stem; layer 4 receives projections from the thalamus; and layers 2 and 3 send projections to other cortical areas. Progress is just beginning to be made in the molecular specification of cortical laminar identity $(53,54)$. A critical unanswered question is how the gradients of transcription factor expression in cortical progenitors are translated into discontinuous molecular features within

A B
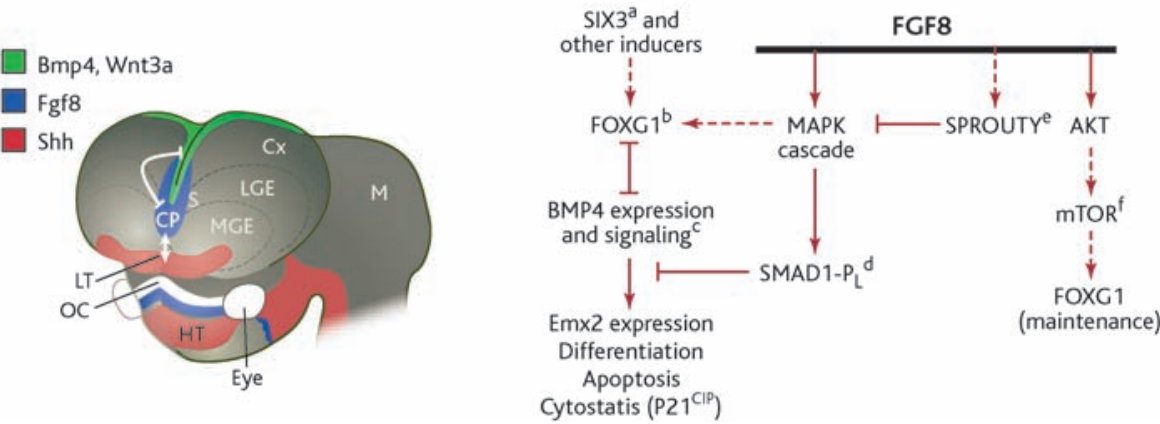

Fig. 2. (A) Rostrolateral view of a mouse brain at about 10.5 embryonic days, highlighting the patterning centers. White arrows, positive interactions; white lines with bars, repressive interactions (23); CP, commissural plate; Cx, Cortex; HT, hypothalamus; LT, lamina terminalis; LGE, lateral ganglionic eminence; MGE, medial ganglionic eminence; $M$, mesencephalon; OC, optic chiasm. (B) Selected signaling cascades downstream of Fgf8 that regulate expression of key transcription factors Emx2 and Foxg1. Dotted lines indicate indirect steps. Not shown: Fgf8 represses Wnt expression. For steps a, b, c, d, e, and f, see, respectively, (137), (40), (138), (139), (29), and (140). 
whereas motor thalamus axons enter the rostral cortex) (58). For instance, mice with defects in the basal ganglia (Ebf1), or the basal ganglia and prethalamus (Dlx1/2), have systematic errors in the topography of thalamic projections to the prenatal cortex; their immature somatosensory thalamus projects axons to the region of the immature visual cortex $(3,59,60)$. Gradients of EphrinA5 in the basal ganglia and EphA4 in the thalamus contribute key molecular cues for organizing this topography (61).

The growth of thalamic axons to the cortex appears to be influenced by axons growing from the cortex to the thalamus. Mice with a paucity of normal corticothalamic axons (Tbr1 mutants) show a defect in the growth of thalamic axons to the cortex (53). This and related findings are consistent with some of the postulates of the "handshake hypothesis" (58) and with the proposal that the topography of thalamocortical axons is regulated in part by interactions with their environment during development (Fig. 1). Furthermore, thalamic afferents grow through cortical progenitors in the subventricular zone, where the axons have been postulated to regulate the cell-cycle kinetics that contribute to histological differences between primate visual areas 17 and 18 (62).

\section{Specificity of Thalamocortical and Intracortical Connections}

Innervation of cortical areas by thalamic axons is the first step in creating processing circuits within the cortex (58). Subsequently, interlaminar connections between cortical neurons within a column, together with local and long-range connections, form the major networks that are characteristic of a cortical area and that transform inputs into outputs that are conveyed to other cortical or subcortical structures.

An important step in innervation of the cortex by thalamic axons is innervation of the deepest cortical layer, the subplate $(63,64)$. In the subplate, thalamic axons "wait" for cortical layer 4 neurons to migrate and settle before entering the cortical plate and making contact with these target cells $(65,66)$. Ablation of the subplate prevents the formation of ocular dominance columns (67) as well as
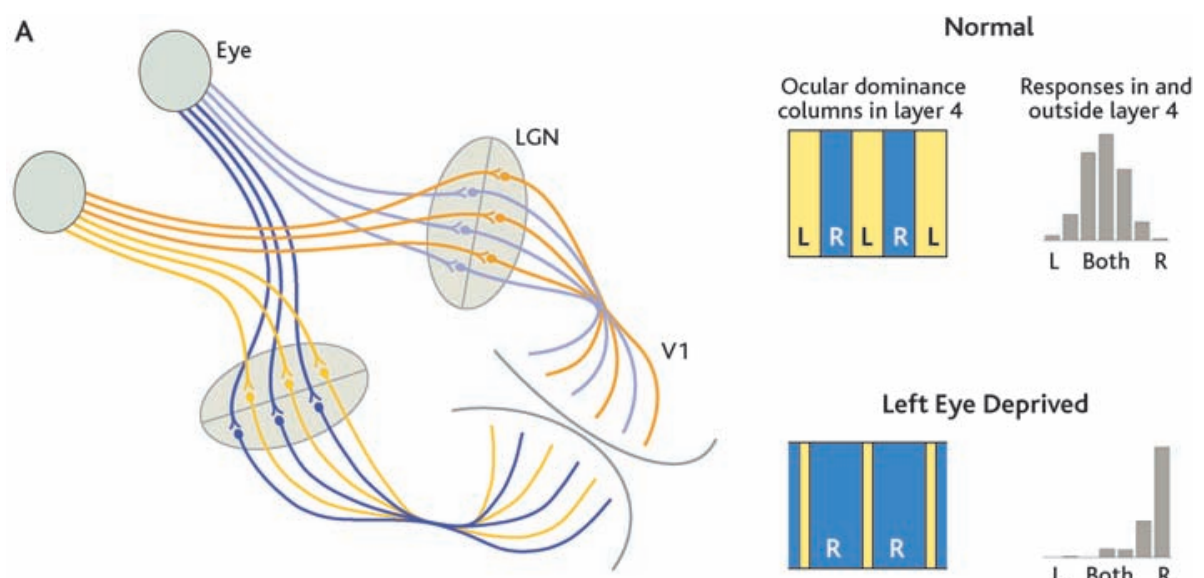

B
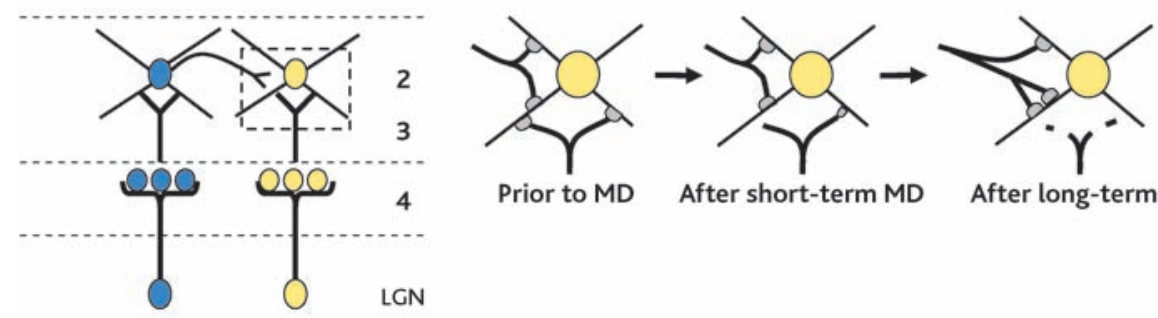

Prior to MD

After short-term MD

After long-term MD

Non-deprived Deprived

Fig. 3. Activity shapes connections in visual cortex. (A) Projections from the two retinas are targeted to the thalamic lateral geniculate nucleus (LGN) and subsequently to the primary visual cortex (V1). In higher mammals, the projections form alternating columns within layer 4, representing inputs from the right and left eyes, respectively. Suturing one eye shrinks its columns and causes cortical cells to respond nearly exclusively to the open eye. Adapted from $(91,92)$. (B) Functional and structural changes after monocular deprivation occur rapidly in the superficial and deep layers of cortex (109). The first changes are a reduction in size and loss of spines (gray ovals) driven by the deprived eye (107). Deprivation for a longer period causes a more significant loss of spines driven by the deprived eye (110), shrinkage of deprived eye axon arbors (dashed line connecting upward), and an expansion of connections from the nondeprived eye. These intracortical changes likely precede similar changes in thalamocortical connections, shown in (A). orientation-selective cells and orientation columns (68). More generally, signals in both the subplate and the cortical plate have a role in directing the growth of thalamic axons, as shown in experiments in which an ectopic somatosensory cortex is generated by ectopic Fgf8 (30).

The cortex has remarkably specific interlaminar and intralaminar connections between individual cells and cell classes (69-73). Layer 5 neurons in somatosensory or visual cortex receive interlaminar inputs from specific cells (74), form stereotyped local connections (75), and develop specific early long-distance projections (76). A subset of strong intracortical connections exists within a set of weaker connections, the latter providing a potential substrate for synaptic strengthening and network plasticity (77). Fine-scale connections and specific sparse connections characterize interlaminar networks $(72,73)$. Positional cues within individual cortical layers regulate the formation of layer-specific projections, probably through diffusible or membrane-associated molecules (78). Semaphorin/neuropilin and ephrin/eph ligand/receptor proteins are implicated in directing specific aspects of axonal and dendritic growth. For example, semaphorin $3 \mathrm{a}$ is expressed in the superficial cortical plate, where it can repulse pyramidal cell axons (79) and attract their apical dendrites $(80)$.

\section{Activity-Dependent Mechanisms of Network Formation and Plasticity}

A scaffold of cell-specific connections and hence of area-specific networks may be laid down by molecular recognition and adhesion mechanisms, perhaps using splice variants of cell adhesion proteins such as cadherins (81) and neurexins (82). Superimposed on this framework, activity-dependent mechanisms shape connections between neurons.

Spontaneous electrical activity is present at the earliest stages of cortical development, and stimulus-driven activity in sensory pathways is particularly prominent at later stages of development. Electrical activity can be permissive, to trigger molecular or developmental programs that create connections, or instructive, to shape particular connections or their strength. Activity operates through modulating the expression and function of almost the entire range of molecules responsible for neuronal and synaptic function [see, for example, (83)]. Activitydependent regulation of synaptic strength (plasticity) may be a manifestation of intrinsic homeostatic mechanisms to preserve a particular level of synaptic drive (84). Thus, for later stages in cortical development, the line between "activity-independent" and "activity-dependent" mechanisms of development is increasingly becoming blurred. Intracortical connections, which form later than 
thalamocortical connections, also exhibit protracted plasticity $(85,86)$.

Studies that alter inputs to primary sensory cortices have been fundamental for understanding activity-dependent mechanisms that regulate development of neuronal circuits. For brevity, here we will focus on two components of the primary visual cortex (V1): ocular dominance columns and orientation columns. The formation of these circuits illustrates the interplay between early developmental scaffolds and later patterned electrical activity in shaping local and long-range (tangential) intracortical networks.

Ocular dominance columns in V1-domains driven by either the left or right eye-arise by the segregation of retinal inputs relayed through eye-specific layers of the lateral geniculate nucleus (Fig. 3A, left). The initial ingrowth of axons into visual cortex from eye-specific thalamic layers targets eye-specific cortical domains (87-89), which suggests the existence of molecular cues that underlie the formation of ocular dominance columns. However, activitydependent mechanisms are required to consolidate the patterning and establish the connectivity of eye-specific projections. Suturing the lids of one eye during a critical period early in life reduces the size of ocular dominance columns related to the sutured eye (Fig. $3 \mathrm{~A}$, right) (90-92). These experiments demonstrate ocular dominance plasticity, whereby the open or untreated eye dominates the cortex both physiologically and anatomically, presumably through competition between axons from the two eyes for cortical territory and synaptic linkage with target cells.

Ocular dominance plasticity is also shaped by the activity of local circuit neurons. Basket cells, GABAergic inhibitory neurons with widespread axonal collaterals, are critical for mediating the plasticity, through synapses containing alphal GABAergic receptors on pyramidal cells (93). Similarly, modulating GABAergic inhibition in visual cortex of cats alters the spacing and periodicity of ocular dominance columns (94): Enhancing inhibition increases ocular dominance column width. Thus, these studies implicate lateral inhibitory interactions in specific aspects of functional connectivity and structural patterning within visual cortex.

Cortical cells and networks seek to preserve a balance between excitation and inhibition as they develop synaptic connections (95). A critical level of inhibition is required for initiating and terminating ocular dominance plasticity (96); disrupting the balance by even subtle manipulation of inhibition alters functional and structural connections within cortical networks. Similarly, cortical neurons seek to maintain a given level of synaptic drive by scaling their inputs in homeostatic fashion (97). The effects of various manipulations of visual activity, including monocular deprivation and dark-rearing, can be understood within the framework of these mechanisms that operate during normal development to organize cortical connections $(84,96)$.

How might electrical activity influence the structural organization of cortical connections? A critical locus of both physiological and anatomical change is at the level of dendritic spines, which are structural specializations that contain the postsynaptic elements of excitatory synapses [for a review, see (98)]. In vitro, long-term potentiation is correlated with enlargement of spines and addition of new spines $(99,100)$, whereas long-term depression is correlated with shrinkage of spines (101); these shape changes are mediated in part through the degree of actin polymerization $(102,103)$. In vivo, spine numbers on somatosensory cortex neurons are reduced if their afferent inputs are removed either during development or during adulthood $(104,105)$. Thus, reduction of synaptic drive may be sufficient to destabilize and reorganize spine structure and number.

Activity rapidly alters dendritic spines $(106,107)$ and synaptic connections $(108,109)$

A

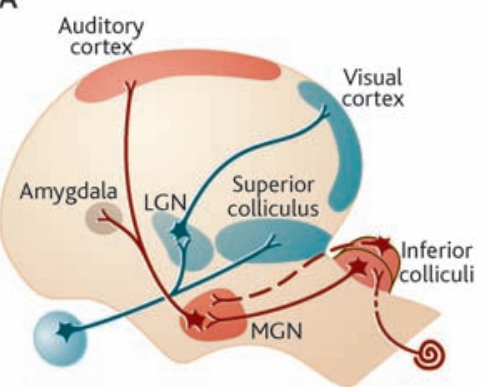
B
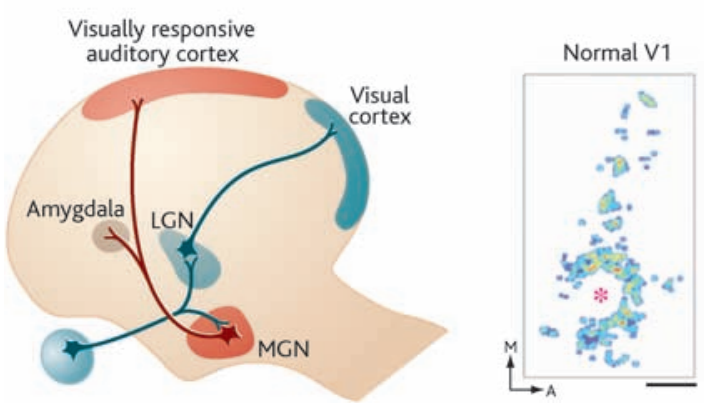

Horizontal connections
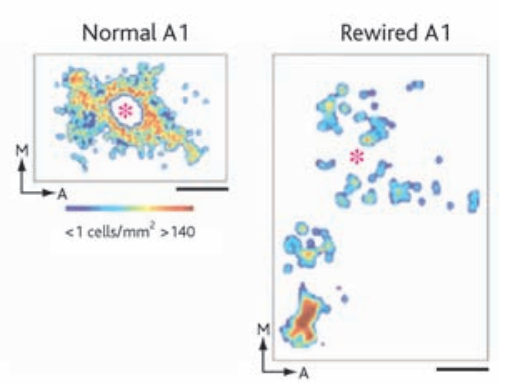

Fig. 4. Induction of function in cortex by novel activity. (A) Visual and auditory pathways in normal ferrets (top) originate from the retina and cochlea, respectively. Eliminating inferior colliculus projections to the medial geniculate nucleus (MGN) in neonatal animals results in retinal fibers innervating the MGN (bottom). The MGN still projects to the auditory cortex and amygdala but now relays visual information. Adapted from (130) and (135). (B) The orientation map in primary visual cortex (V1) of a normal ferret and in auditory cortex (A1) of a rewired ferret, revealed by optical imaging. The color of each pixel represents the stimulus orientation yielding the best response at that pixel (according to the key at right). As in normal V1, the map in rewired A1 contains pinwheels (within dotted circles) around which cells preferring different orientations are systematically represented (133). Scale bar, $0.5 \mathrm{~mm}$. (C) Horizontal connections in ferret cortex. In V1, horizontal connections labeled with an injection of cholera toxin B (at starred site) in the superficial layers are patchy and link cells with similar orientation preference. In A1, horizontal connections spread along the isofrequency axis of cortex. In rewired A1, horizontal connections are patchy and resemble connections in V1. Colors indicate density of labeled cells according to the key at center. Scale bars, $0.5 \mathrm{~mm}$. Adapted from (133). 
geniculate nucleus that are aligned along the axis of orientation $(114,115)$, although considerable evidence indicates that local intracortical excitation and balanced inhibition is critical for generating sharp orientation selectivity $(116,117)$. Orientation-selective cells in at least the superficial layers of V1 are organized into an orientation map (118). Within the map, domains of cortical neurons that prefer a particular orientation are preferentially linked by long-range horizontal connections (119).

Orientation selectivity is present in V1 of monkeys at birth (120) and in cats and ferrets at eye-opening, although selectivity sharpens with visual experience $(121,122)$. Visual deprivation impairs, but does not completely prevent, the development of orientation-selective responses $(121,122)$. Although long-range horizontal connections are present in cats and ferrets just before eye-opening, the refinement of these connections depends on visual experience (123-125). Short-term monocular lid suture, after the orientation map has formed, leads to deterioration of the map driven by the closed eye; however, reopening the closed eye early in life restores the map $(126,127)$. Thus, similar to ocular dominance columns, orientation selectivity and orientation maps in V1 may be set up by an early, intrinsic scaffold of connections that is later shaped by activity. Indeed, the orientation map forms synergistically with the maps of visual space and ocular dominance (128) and influences plasticity of orientation tuning in adult V1 (129).

Exposure of the cortex to novel sensory information provides complementary insights into the role of activity in development of orientation networks (130). Rearing kittens under conditions in which they view one particular orientation causes an overrepresentation of that orientation in V1 (131). Rewiring retinal inputs into the developing auditory thalamus causes auditory cortex to be driven by visual activity (Fig. 4A) (132). Primary auditory cortex in "rewired" ferrets develops visual orientation-selective cells and an orientation map (Fig. 4, B and C), with considerable reorganization of horizontal connections in a manner that supports the novel map (133). Yet, the connections retain vestiges of connections in normal auditory cortex, and the orientation map remains somewhat poorer than that in normal visual cortex (Fig. 4 B and C). Thus, visually driven activity interacts dynamically with earlier or ongoing developmental programs to shape network connections in the rewired cortex.

Finally, the novel projection from the retina to the auditory thalamus in rewired animals can profoundly affect behavior. Rewired ferrets trained to discriminate a visual from an auditory cue can perceive a visual cue as visual when the auditory cortex is activated by vision (134). Through direct activation of the amygdala via the auditory thalamus, rewired mice rapidly learn a visually cued conditioned fear response in a time comparable to an auditory cue (and much faster than a visual cue) in normal mice (135). Thus, the modality of inputs to the auditory thalamus can instruct the function of subsequent targets. Therefore, genetically determined brain pathways and cortical regions that are established during early development depend on their inputs for physiological and behavioral instruction.

\section{Conclusions}

The Protomap/Protocortex controversy no longer remains: It is clear that the parcellation of the cerebral cortex into discrete processing areas involves an interwoven cascade of developmental events including both intrinsic and extrinsic mechanisms. The field now has the intellectual foundation and tools that will enable it to elucidate more complex features of cortical development, such as the formation of higher order cortical areas and circuits (which are a robust feature of the primate brain) and the lateralization of cortical functions (136). Insights gained from such studies will undoubtedly facilitate understanding of the mechanisms underlying the evolution of neural systems that control cognition and emotion as well as the etiologies of disorders that derail them.

\section{References and Notes}

1. P. Rakic, Science 241, 170 (1988).

2. D. D. O'Leary, Trends Neurosci. 12, 400 (1989).

3. S. Garel, J. L. R. Rubenstein, in The Cognitive Neurosciences, M. S. Gazzaniga, Ed. (MIT Press, Cambridge, MA, ed. 3rd, 2004), pp. 69-84.

4. L. Puelles, J. L. Rubenstein, Trends Neurosci. 26, 469 (2003).

5. P. H. Crossley, S. Martinez, Y. Ohkubo, J. L. Rubenstein Neuroscience 108, 183 (2001).

6. C. W. Ragsdale, E. A. Grove, Curr. Opin. Neurobiol. 11, 50 (2001).

7. D. D. O'Leary, Y. Nakagawa, Curr. Opin. Neurobiol. 12,14 (2002).

8. T. Shimogori, V. Banuchi, H. Y. Ng, J. B. Strauss, E. A. Grove, Development 131, 5639 (2004).

9. Y. Ohkubo, C. Chiang, J. L. Rubenstein, Neuroscience 111,1 (2002).

10. K. Aoto, T. Nishimura, K. Eto, J. Motoyama, Dev. Biol. 251, 320 (2002).

11. M. Rallu et al., Development 129, 4963 (2002).

12. E. A. Grove, S. Tole, J. Limon, L. Yip, C. W. Ragsdale, Development 125, 2315 (1998).

13. Y. Furuta, D. W. Piston, B. L. Hogan, Development 124, 2203 (1997).

14. S. M. Lee, S. Tole, E. Grove, A. P. McMahon, Development 127, 457 (2000).

15. J. Galceran, E. M. Miyashita-Lin, E. Devaney, J. L. Rubenstein, R. Grosschedl, Development 127, 469 (2000).

16. J. M. Herbert, Y. Mishina, S. K. McConnell, Neuron 35, 1029 (2002)

17. R. M. Anderson, A. R. Lawrence, R. W. Stottmann, D. Bachiller, J. Klingensmith, Development 129, 4975 (2002).

18. P. J. Blackshear et al., Development 130, 4539 (2003).

19. T. Fukuchi-Shimogori, E. A. Grove, Science 294, 1071 (2001)

20. S. Garel, K. J. Huffman, J. L. Rubenstein, Development 130, 1903 (2003).
21. S. Shanmugalingam et al., Development 127, 2549 (2000).

22. K. Shimamura, J. L. Rubenstein, Development 124, 2709 (1997)

23. E. E. Storm, J. L. Rubenstein, G. R. Martin, Proc. Natl. Acad. Sci. U.S.A. 100, 1757 (2003).

24. Y. Maruoka et al., Mech. Dev. 74, 175 (1998).

25. J. Walshe, I. Mason, Development 130, 4337 (2003).

26. E. A. Grove, T. Fukuchi-Shimogori, Annu. Rev. Neurosci. 26, 355 (2003).

27. M. Shinya, S. Koshida, A. Sawada, A. Kuroiwa, H. Takeda, Development 128, 4153 (2001)

28. T. Fukuchi-Shimogori, E. A. Grove, Nat. Neurosci. 6, 825 (2003).

29. H. J. Kim, D. Bar-Sagi, Nat. Rev. Mol. Cell Biol. 5, 441 (2004).

30. T. Shimogori, E. A. Grove, J. Neurosci. 25, 6550 (2005).

31. A. Stoykova, P. Gruss, J. Neurosci. 14, 1395 (1994).

32. H. Toresson, S. S. Potter, K. Campbell, Development 127, 4361 (2000).

33. K. M. Bishop, G. Goudreau, D. D. O'Leary, Science 288, 344 (2000)

34. K. Yun, S. Potter, J. L. Rubenstein, Development 128, 193 (2001).

35. E. S. Monuki, C. A. Walsh, Nat. Neurosci. 4, (Suppl), 1199 (2001).

36. L. Muzio et al., Cereb. Cortex 12, 129 (2002).

37. L. Muzio, A. Mallamaci, J. Neurosci. 25, 4435 (2005).

38. W. Ye, K. Shimamura, J. L. Rubenstein, M. A. Hynes, A. Rosenthal, Cell 93, 755 (1998).

39. E. S. Monuki, F. D. Porter, C. A. Walsh, Neuron 32, 591 (2001).

40. C. L. Dou, S. Li, E. Lai, Cereb. Cortex 9, 543 (1999).

41. S. Kuschel, U. Ruther, T. Theil, Dev. Biol. 260, 484 (2003).

42. S. Tole, C. W. Ragsdale, E. A. Grove, Dev. Biol. 217, 254 (2000).

43. H. Toresson, K. Campbell, Development 128, 4769 (2001).

44. K. Yun et al., Development 129, 5029 (2002).

45. J. M. Stenman, B. Wang, K. Campbell, J. Neurosci. 23, 10568 (2003).

46. C. Zhou, S. Y. Tsai, M. J. Tsai, Genes Dev. 15, 2054 (2001).

47. K. M. Bishop, J. L. Rubenstein, D. D. O'Leary, J. Neurosci. 22, 7627 (2002)

48. A. Mallamaci, L. Muzio, C. H. Chan, J. Parnavelas, E. Boncinelli, Nat. Neurosci. 3, 679 (2000).

49. T. Hamasaki, A. Leingartner, T. Ringstedt, D. D. O'Leary, Neuron 43, 359 (2004).

50. K. M. Bishop, S. Garel, Y. Nakagawa, J. L. Rubenstein, D. D. O'Leary, J. Comp. Neurol. 457, 345 (2003).

51. K. Shinozaki, M. Yoshida, M. Nakamura, S. Aizawa, Y. Suda, Mech. Dev. 121, 475 (2004).

52. O. Marin, J. L. Rubenstein, Annu. Rev. Neurosci. 26, 441 (2003).

53. R. F. Hevner, E. Miyashita-Lin, J. L. Rubenstein, J. Comp. Neurol. 447, 8 (2002).

54. C. Schuurmans et al., EMBO J. 23, 2892 (2004).

55. E. M. Miyashita-Lin, R. Hevner, K. M. Wassarman, S Martinez, J. L. Rubenstein, Science 285, 906 (1999).

56. D. Uziel et al., J. Neurosci. 22, 9352 (2002).

57. K. J. Huffman, S. Garel, J. L. Rubenstein, J. Neurosci. 24, 8917 (2004).

58. G. Lopez-Bendito, Z. Molnar, Nat. Rev. Neurosci. 4, 276 (2003).

59. S. Garel, K. Yun, R. Grosschedl, J. L. Rubenstein, Development 129, 5621 (2002)

60. S. Garel, J. L. Rubenstein, Trends Neurosci. 27, 533 (2004).

61. A. Dufour et al., Neuron 39, 453 (2003).

62. I. H. Smart, C. Dehay, P. Giroud, M. Berland, H. Kennedy, Cereb. Cortex 12, 37 (2002)

63. K. Herrmann, C. J. Shatz, Proc. Natl. Acad. Sci. U.S.A. 92, 11244 (1995).

64. E. Friauf, S. K. McConnell, C. J. Shatz, J. Neurosci. 10, 2601 (1990).

65. C. J. Shatz, M. B. Luskin, J. Neurosci. 6, 3655 (1986).

66. P. Rakic, Philos. Trans. R. Soc. Lond. B Biol. Sci. 278, 245 (1977).

67. A. Ghosh, A. Antonini, S. K. McConnell, C. J. Shatz, Nature 347, 179 (1990).

68. P. O. Kanold, P. Kara, R. C. Reid, C. J. Shatz, Science 301, 521 (2003) 
69. F. Briggs, E. M. Callaway, J. Neurosci. 21, 3600 (2001)

70. E. M. Callaway, Annu. Rev. Neurosci. 21, 47 (1998).

71. C. D. Gilbert, J. Physiol. 268, 391 (1977).

72. Y. Yoshimura, J. L. Dantzker, E. M. Callaway, Nature 433, 868 (2005)

73. G. M. Shepherd, A. Stepanyants, I. Bureau, D. Chklovskii, K. Svoboda, Nat. Neurosci. 8, 782 (2005).

74. D. Feldmeyer, A. Roth, B. Sakmann, J. Neurosci. 25, 3423 (2005)

75. J. Kozloski, F. Hamzei-Sichani, R. Yuste, Science 293, 868 (2001).

76. F. Clasca, A. Angelucci, M. Sur, Proc. Natl. Acad. Sci. U.S.A. 92, 11145 (1995)

77. S. Song, P. J. Sjostrom, M. Reigl, S. Nelson, D. B. Chklovskii, PLoS Biol. 3, e68 (2005)

78. V. Castellani, J. Bolz, Proc. Natl. Acad. Sci. U.S.A. 94, 7030 (1997)

79. F. Polleux, R. J. Giger, D. D. Ginty, A. L. Kolodkin, A. Ghosh, Science 282, 1904 (1998).

80. F. Polleux, T. Morrow, A. Ghosh, Nature 404, 567 (2000).

81. Y. Iwai et al., Mol. Cell. Neurosci. 19, 375 (2002).

82. K. Tabuchi, T. C. Sudhof, Genomics 79, 849 (2002)

83. H. Cline, Trends Neurosci. 26, 655 (2003).

84. G. G. Turrigiano, S. B. Nelson, Nat. Rev. Neurosci. 5, 97 (2004)

85. N. B. Sawtell et al., Neuron 38, 977 (2003).

86. V. Dragoi, M. Sur, in The Visual Neurosciences, L. Chalupa, J. Werner, Eds. (MIT Press, Cambridge, MA, 2004), vol. 2, pp. 1654-1664.

87. M. C. Crair, J. C. Horton, A. Antonini, M. P. Stryker, J. Comp. Neurol. 430, 235 (2001).

88. J. C. Crowley, L. C. Katz, Science 290, 1321 (2000).

89. J. C. Crowley, L. C. Katz, Nat. Neurosci. 2, 1125 (1999).

90. A. Antonini, M. P. Stryker, Science 260, 1819 (1993).

91. T. N. Wiesel, D. H. Hubel, J. Neurophysiol. 28, 1029 (1965).

92. C. J. Shatz, M. P. Stryker, J. Physiol. 281, 267 (1978)

93. M. Fagiolini et al., Science 303, 1681 (2004).

94. T. K. Hensch, M. P. Stryker, Science 303, 1678 (2004).

95. G. Liu, Nat. Neurosci. 7, 373 (2004).

96. T. K. Hensch, Annu. Rev. Neurosci. 27, 549 (2004)
97. N. S. Desai, R. H. Cudmore, S. B. Nelson, G. G. Turrigiano, Nat. Neurosci. 5, 783 (2002).

98. H. Hering, M. Sheng, Nat. Rev. Neurosci. 2, 880 (2001).

99. M. Maletic-Savatic, R. Malinow, K. Svoboda, Science 283, 1923 (1999).

100. F. Engert, T. Bonhoeffer, Nature 399, 66 (1999).

101. Q. Zhou, K. J. Homma, M. M. Poo, Neuron 44, 749 (2004).

102. K. I. Okamoto, T. Nagai, A. Miyawaki, Y. Hayashi, Nat. Neurosci. 7, 1104 (2004).

103. M. Matsuzaki, N. Honkura, G. C. Ellis-Davies, H. Kasai, Nature 429, 761 (2004)

104. J. T. Trachtenberg et al., Nature 420, 788 (2002)

105. B. Lendvai, E. A. Stern, B. Chen, K. Svoboda, Nature 404, 876 (2000)

106. A. Majewska, M. Sur, Proc. Natl. Acad. Sci. U.S.A. 100, 16024 (2003).

107. S. Oray, A. Majewska, M. Sur, Neuron 44, 1021 (2004).

108. J. T. Trachtenberg, M. P. Stryker, J. Neurosci. 21, 3476 (2001).

109. J. T. Trachtenberg, C. Trepel, M. P. Stryker, Science 287, 2029 (2000)

110. N. Mataga, Y. Mizuguchi, T. K. Hensch, Neuron 44 1031 (2004).

111. R. Lamprecht, J. LeDoux, Nat. Rev. Neurosci. 5, 45 (2004).

112. N. Mataga, N. Nagai, T. K. Hensch, Proc. Natl. Acad. Sci. U.S.A. 99, 7717 (2002).

113. N. Berardi, T. Pizzorusso, G. M. Ratto, L. Maffei, Trends Neurosci. 26, 369 (2003)

114. D. H. Hubel, T. N. Wiesel, J. Physiol. 195, 215 (1968).

115. D. Ferster, K. D. Miller, Annu. Rev. Neurosci. 23, 441 (2000).

116. D. C. Somers, S. B. Nelson, M. Sur, J. Neurosci. 15 5448 (1995).

117. J. Marino et al., Nat. Neurosci. 8, 194 (2005).

118. T. Bonhoeffer, A. Grinvald, Nature 353, 429 (1991)

119. C. D. Gilbert, T. N. Wiesel, J. Neurosci. 9, 2432 (1989).

120. T. N. Wiesel, D. H. Hubel, J. Comp. Neurol. 158 307 (1974).

121. B. Chapman, M. P. Stryker, J. Neurosci. 13, 5251 (1993).
122. B. Chapman, I. Godecke, T. Bonhoeffer, J. Neurobiol. 41, 18 (1999)

123. E. S. Ruthazer, M. P. Stryker, J. Neurosci. 16, 7253 (1996).

124. E. M. Callaway, L. C. Katz, Proc. Natl. Acad. Sci. U.S.A. 88, 745 (1991).

125. L. E. White, D. M. Coppola, D. Fitzpatrick, Nature 411, 1049 (2001)

126. D.-S. Kim, T. Bonhoeffer, Nature 370, 370 (1994).

127. I. Godecke, T. Bonhoeffer, Nature 379, 251 (1996).

128. H. Yu, B. J. Farley, D. Z. Jin, M. Sur, Neuron 47, 267 (2005).

129. V. Dragoi, C. Rivadulla, M. Sur, Nature 411, 80 (2001).

130. M. Sur, C. A. Leamey, Nat. Rev. Neurosci. 2, 251 (2001)

131. F. Sengpiel, P. Stawinski, T. Bonhoeffer, Nat. Neurosci. 2, 727 (1999).

132. M. Sur, in Handbook of Multisensory Processes, G. Calvert, C. Spence, B. E. Stein, Eds. (MIT Press, Cambridge, MA, 2004), pp. 681-694.

133. J. Sharma, A. Angelucci, M. Sur, Nature 404, 841 (2000).

134. L. von Melchner, S. L. Pallas, M. Sur, Nature 404 871 (2000)

135. J. R. Newton, C. Ellsworth, T. Miyakawa, S. Tonegawa M. Sur, Nat. Neurosci. 7, 968 (2004).

136. T. Sun et al., Science 308, 1794 (2005).

137. O. V. Lagutin et al., Genes Dev. 17, 368 (2003).

138. J. Seoane, H. V. Le, L. Shen, S. A. Anderson, J. Massague, Cell 117, 211 (2004).

139. E. M. Pera, A. Ikeda, E. Eivers, E. M. De Robertis, Genes Dev. 17, 3023 (2003)

140. K. E. Hentges et al., Proc. Natl. Acad. Sci. U.S.A. 98 13796 (2001).

141. Supported by grants from $\mathrm{NIH}$, the Marcus Fund, and the Simons Foundation (M.S.); Nina Ireland Laboratory of Developmental Neurobiology, and the Hillblom Foundation, and a K05 award from NIMH (J.L.R.R.). We thank M. Brouillette and M. Potak for their help.

$10.1126 /$ science. 1112070

\title{
R E V I E W
}

\section{Map Plasticity in Somatosensory Cortex}

\author{
Daniel E. Feldman ${ }^{1 *}$ and Michael Brecht ${ }^{2}$
}

\begin{abstract}
Sensory maps in neocortex are adaptively altered to reflect recent experience and learning. In somatosensory cortex, distinct patterns of sensory use or disuse elicit multiple, functionally distinct forms of map plasticity. Diverse approaches-genetics, synaptic and in vivo physiology, optical imaging, and ultrastructural analysis-suggest a distributed model in which plasticity occurs at multiple sites in the cortical circuit with multiple cellular/synaptic mechanisms and multiple likely learning rules for plasticity. This view contrasts with the classical model in which the map plasticity reflects a single Hebbian process acting at a small set of cortical synapses.
\end{abstract}

A fundamental feature of neural circuits is the capacity for plasticity in response to experience or learning. A classic system for studying plasticity is primary somatosensory (S1) cortex. Somatosensory maps in S1 are highly plastic, both during development $(1,2)$ and

1Division of Biological Sciences, University of California, San Diego, 9500 Gilman Drive, Room 0357, La Jolla, CA 92093, USA. ${ }^{2}$ Department of Neuroscience, Erasmus MC, Postbus 1738, 3000 DR Rotterdam, Netherlands.

*To whom correspondence should be addressed. E-mail: dfeldman@ucsd.edu in adult animals (3). Plasticity occurs in response to peripheral lesions, passive sensory experience, and training on sensory tasks and is correlated with sensory perceptual learning. The underlying cellular mechanisms for map plasticity and its consequences for cortical processing are highly relevant to development, learning, and recovery of function after injury.

Rodent S1 cortex has emerged as a key model system in the analysis of the forms and mechanisms of map plasticity because of several experimental advantages. First, rodent S1 contains an orderly map of the large facial whiskers, which act as active tactile detectors, and large-scale map plasticity can be simply induced by trimming or plucking subsets of whiskers. Second, layer 4 (L4) of S1 contains an anatomical map of cell clusters, called "barrels," that is isomorphic to the arrangement of whiskers on the snout (4). Barrels can be visualized in brain slices, allowing cells and circuits at specific locations in the whisker map to be investigated in detail in vitro (5). Third, the superficial location of S1 allows live, optical imaging of neuronal function and structure, as well as whole-cell recording to study subthreshold events in vivo. Finally, molecular mechanisms of plasticity can be tackled using mouse genetics (6). Research on barrel cortex plasticity is particularly fascinating because of the wide range of techniques (7) - genetics, cell biology, in vitro and in vivo physiology, optical imaging - that are applied in the field. Here, we present an emerging consensus from these techniques that map plasticity is a distributed, multifaceted 